\title{
EDUCAÇÃO DEMOCRÁTICA EM TEMPOS PANDÊMICOS
}

\author{
Carla Chagas Ramalho ${ }^{\mathrm{i}}$
}

RESUMO: Este artigo é embasado em ideais e princípios histórico críticos. Nesta visão, as escolas servem como Aparelhos Ideológicos do Estado, e por este motivo é primordial mostrar a importância da democracia, no seu sentido literal, nesses espaços em tempos pandêmicos. Assim, este trabalho teve por objetivo refletir sobre o valor da educação escolarizada em tempos de pandemia. Foi utilizada como metodologia a pesquisa bibliográfica de estudos sobre educação. Como reflexão deste estudo, foi visto a necessidade de uma nova pedagogia onde o foco seja utilizar a realidade da classe trabalhadora neste momento como possibilitador primário para conscientização de classe, mas cientes que a escola, sozinha, não conseguirá trazer transformações profundas para a sociedade.

Palavras-chave: Educação; Democracia; Pandemia.

\section{DEMOCRATICEDUCATION IN PANDEMIC TIMES}

ABSTRACT: Thisarticleisbasedoncriticalhistoricalidealsandprinciples. In thisvision, schools serve as ideologicalapparatusesofthestate, and for thisreason it isessentialto show theimportanceofdemocracy, in its literalsense, in thesespaces in pandemic times. Thus, thisworkaimedtoreflectonthevalueofschooleducation in times ofpandemic. Bibliographicalresearchofstudiesoneducationwasused as a methodology. As a reflectionofthisstudy, wesawtheneed for a new pedagogywherethefocusisto use the reality oftheworkingclassatthis time as a primaryenabler for classawareness, butawarethatschoolalonewillnotbeabletobringprofoundchangestosociety.

Keywords: Education; Democracy; Pandemic.

\section{Introdução}

Em mais uma manhã de isolamento social, via o telejornal e me deparei com uma reportagem sobre a visitação online de diversos museus pelo mundo ${ }^{\mathrm{ii}}$. A reportagem falava como é possível conhecer diversos museus, dos mais tradicionais aos mais modernos, numa tarde se teria a possibilidade de conhecer museus situados no Brasil e na França, por exemplo. O que seria impossível de forma presencial. Ótima democratização de conhecimento e cultura! Sem as despesas de comprar passagens, se preocupar com hotéis, ou ainda passaportes. Maravilhoso, eu pensei nesse instante.

Porém, minha ficha caiu. Essa democratização tem limites e limitações, não há como todas as pessoas acompanharem estas visitações, porque não são todas que possuem internet de boa qualidade. E mais, mesmo que se todos os cidadãos e cidadãs tenham este tal acesso, a 
cibertrasmissão substitui estar presente, fisicamente, em tais espaços? Sentir o clima diferente de outros locais, analisar as obras de arte e ter a percepção dos seus tamanhos diretamente, sentir o cheiro do local e ter a magnitude dos ambiente históricos sem intermediários. Então problematizei: será que a possibilidade (para alguns e algumas) do acesso virtual, substitui vivenciar o processo no local? Qual é a sensação de estar tão próximo(a) a grandes obras da humanidade? Nunca poderemos saber com a vivência virtual, por mais que narrem, a sensação e a sensibilidade é única.

Sem misturar alhos com bugalhos, mas entendendo que o conhecimento e a aprendizagem não são feitas dentro de caixinhas, fiz a relação de tal fato com o momento educacional que passamos. Como a educação (que teimo que deva ser pública, gratuita e de qualidade) pode ser democrática, fazer sentido, ter significados em tempos de isolamento social, no momento que nos encontramos, onde o toque deve ser rejeitado em prol da saúde individual e coletiva? Como ser educador ou educadora em tempos coletivamente difíceis? Como pensar em conteúdos, componentes curriculares, unidades temáticas desmembradas da realidade que nos cerca e que nos apavora pela incerteza de não sabermos qual futuro estará reservado para o mundo, para nosso país, para nossa casa e familiares?

Com estas inquietações, este estudo tem por objetivo refletir sobre o valor da educação escolarizada em tempos de pandemia. Para alcançar esses objetivos, faremos um estudo qualitativo, embasado na pesquisa bibliográfica (GIL, 2008) com o intuito de remeter a diversos(as) pesquisadores(as) que se embasam na estrutura histórico crítica da área educacional e que auxiliam a apontar possibilidades democráticas neste contexto. O enfoque da literatura pesquisada será voltado para autoras(es) que primam por um projeto de educação de qualidade, onde haja um processo de aprendizado crítico, humano e real, como textos de Althusser (1980) para embasar a lógica da escola como Aparelho Ideológico do Estado; Santos (2020) que nos aponta como a democracia em prol do povo e o sistema capitalista são antagônicos; Saviani $(2011 ; 2012)$ para conceituar a educação histórico crítica; como também Quijano (2002) para apontar que a democracia capitalista vigente há uma aceitação para haver dominados(as) e dominantes.Mesmo que alguns desses autores não falem especificamente sobre a realidade atual, de isolamento social e pandemia, servirão de aporte teórico para este trabalho.

Saliento que estudos de cunho crítico se embasam nas lutas de classes, no embate entre opressores e oprimidos que refletem em grupos de explorados(as) e exploradores(as) (MARX; ENGELS, 1999), tendo como foco a classe e não a subjetividade dos sujeitos. O contexto histórico crítico se embasa na sociedade como um todo e prioriza não o senso 


\section{artes de}

educar

comum, mas as explanações criteriosas de estudiosos(as) que se embasam no mesmo ponto de vista; em pesquisadores(as) que compreendem como a diferenciação de possibilidades, ensinamentos, conhecimentos por grupos/classes, reforça e dissemina o ideal do sistema político, econômico, social denominado como capitalismo (SAVIANI, 2011). Então, vamos ao debate e a contextualização desse ideal com o período pandêmico atual.

\section{Democracia nesses tempos}

Estamos habituadas(os) a escutar e a esbravejar a palavra democracia rotineiramente na nossa sociedade, principalmente quando entende-se que a democracia está em perigo, de alguma forma. Mas, antes de fazer uma leitura sobre nosso período atual de pandemia, precisamos pontuar sobre qual democracia estamos falando e pra quem ela serve. Olharei para a democracia com o olhar crítico, buscando fazer uma análise embasada em autores(as) que já fizeram autópsias em sistemas democráticos, esmiuçando detalhes importantes para os tempos atuais.

Precisamos ter consciência que democracia e capitalismo são palavras, termos e vivências que se chocam a todo o momento, só vivem em conformidade quando uma serve a outra e, infelizmente, o que tem ocorrido é a democracia ser moldada para servir princípios e interesses capitalistas. Nota-se com maior clareza esta teoria quando há a constatação que os direitos humanos são violados para poder haver subalternização de serviços e divisão diferenciada de rendas. Mas, tudo ocorre de forma singela, partindo do princípio que não se poderia viver de outra forma, logo, as concessões são vistas como benevolências e são exaltadas pela massa (SANTOS, 2009). Como podemos ver na rica explicação de Santos (2009)

Porque tudo isso ocorre sem uma suspensão formal desses direitos e garantias, estamos perante a emergência de uma nova forma de Estado, o Estado de excepção, que, contrariamente às antigas formas de Estado de sítio ou de Estado de emergência, restringe os direitos democráticos sob o pretexto da sua salvaguarda ou mesmo expansão. (p. 35)

As amarras são multilaterais e tornam-se quase que essenciais para o senso comum e repudia qualquer situação que deixe pessoas livres e capazes de decidirem sozinhas em determinadas situações. Coloca o povo como eterna criança que tem a necessidade do amparo de responsáveis para lhes dizer o que é permitido ou não. Assim, o que é dito é conferido o 


\section{artes de}

educar

poder de ser verdade, sendo pouco questionado, quando questionado, sendo posto em dúvida pela maioria.

Esta democracia é denominada como democracia capitalista (QUIJANO, 2002), onde há o cabresto invisível do poder colonial, que prende e sufoca de maneira negociável e institucionalizada, os limites das sujeições para exploração e dominação, onde a cidadania é demarcada pelo moderno Estado-nação. Nesta concepção democrática, as amarras não prendem para simplesmente te machucar e restringir até onde você pode ir, esta democracia demarca as ações possíveis, dentro de vários contextos institucionalizados, dando as limitações um ar de naturalidade, onde não há o que ser feito.

Nem por isso esta colonização, trazida por Quijano (2002), é mais suave do que as dos tempos do Brasil (declaradamente) colônia, muito pelo contrário. Quando não sentimos estas amarras impostas, quando encaramos a realidade como imutável e natural, não temos noção das possibilidades que nos foram tiradas. Como por exemplo, se você pode optar por escolher uma blusa branca ou preta, pode ter a impressão que esta escolha foi democrática, sem se conscientizar que teriam outras diversas opções de cores que estariam a sua disposição. E, comparativamente, este Estado-nação nos impõe opções que estão entre ruins ou muito ruins, e, habitualmente, a população fica satisfeita por este "poder" de escolha que tem.

Santos (2014) define que há um sequestro da democracia pelo capitalismo financeiro, onde as amarras singelas jogam o holofote nos direitos humanos que são atribuídos, desconsiderando todas as possibilidades que foram cerceadas. Pois, para o sistema político, econômico, social e cultural capitalista vigente, não há como ser garantidor de diversas possibilidades para todas as pessoas, por isso, estabelece-se o direito humano minimamente para todos(as) e fecha os olhos para os que estão a margem do conhecimento efetivo sobre seus direitos.

Assim, a exclusão torna-se simultaneamente radical e inexistente, uma vez que seres sub-humanos não são considerados sequer candidatos à inclusão social. A humanidade moderna não se concebe sem uma sub-humanidade moderna. A negação de uma parte da humanidade é sacrificial, na medida em que constitui a condição para a outro parte da humanidade se afirmar enquanto universal." (SANTOS, 2009, p. 31) [grifo meu]

Fica estabelecida uma sociedade maquiada por direitos humanos a todos(as), mas sem deixar claro qual grupo de "todos(as)" está sendo dirigida. As segmentações são estabelecidas e configuradas como as antigas castas indianas, mas sem o espanto social, rotineiro, que há sobre as mesmas, pois existe uma falsa ideia de que há uma flexibilização social de castas na 
nossa sociedade, mas esse trajeto depende única e exclusivamente de cada indivíduo. Surge assim o termo banalizado da meritocracia, falácia utilizada de forma inescrupulosa por diversos senhores de engenho que tem única e exclusivamente o objetivo de aumentar suas rendas. Analisando a situação atual da sociedade é visível que a meritocracia apenas reforça as desigualdades e mantém hierarquizações (MOREIRA, 2019).

Estas condições nos trazem para os tempos atuais, os espantosos tempos atuais. A máquina capitalista tem criado engrenagens que torna a maioria da sua população escrava sem correntes e grata com o mínimo (bem mínimo) para sobreviver. Os(as) que não se encaixam neste perfil, normalmente, são vistos ou rotulados como rebeldes ou ingratos. Importante deixar claro que não há nada de atípico ou especial em pessoas que não se enquadram no sistema exploratório capitalista, nem há um perfil típico de tais pessoas, pode haver um olhar mais crítico e coletivo para humanidade, mas que não tem como pré-requisito anos de estudos ou classe econômica, o mosaico é bem mais complexo e foge de padrões pré-estipulados de receituários.

Assim, para sustentar a democracia capitalista há a demanda de diversas instituições e acordos de limites exploratórios para algumas pessoas, respeitando as limitações definidas pelos direitos humanos, e, em contra partida, há necessidade da invisibilidade de outra parcela social, necessária para sustentar a acumulação exagerada de um menor grupo. Chegamos no momento previsto por Santos (2009)

\footnotetext{
Como regime social, o fascismo social pode coexistir com a democracia política liberal [democracia capitalista]. Em vez de sacrificar a democracia às exigências do capitalismo global, trivializa a democracia até ao ponto de não ser necessário, nem sequer conveniente, sacrificar a democracia para promover o capitalismo. Trata-se, pois, de um fascismo pluralista e, por isso, de uma forma de fascismo que nunca existiu. De facto, é minha convicção que podemos estar a entrar num período em que as sociedades são politicamente democráticas e socialmente fascistas. (p. 39) [grifo meu]
}

E o atual momento de pandemia, serve como um tenebroso instante de choque, de colapso social, onde algumas situações estão sendo postas como realmente são, fascistas e anti-democráticas. Entendo que essa conjuntura social atual pode vir a ser frutífera, mas ainda não sei se positiva ou negativa; pois, pode ser crucial para desnaturalizar pobrezas extremas (sejam elas econômicas, políticas, morais) ou até mesmo para motivar a aceitação do que o sistema exploratório capitalista "caridosamente" tem a nos oferecer. A história está sendo escrita, conjecturas, hipóteses e possibilidades nos norteiam e mostram a imprevisibilidade que o futuro traz, e por este motivo é preciso ter noção e amplitude do papel de 
professores(as), cidadãos(ãs), responsáveis como também de pessoas preocupadas com a justiça social.

\section{Educação escolar}

Para a definição da educação escolar, trarei Saviani (2011) para uma contextualização necessária sobre o tópico. Respeitando e ampliando o conhecimento sobre a aprendizagem histórico crítica, se faz necessário apontar que a educação nem sempre foi realizada, ou entendida como tal, apenas dentro do ambiente escolar, delimitada pelos muros das escolas. Esta visão parte de uma necessidade de limitação de conhecimento dentro da sociedade burguesa, onde é demarcado os ensinamentos específicos e básicos para as(os) trabalhadoras(es) como também a cientificidade que deve ser atribuída para a classe dominante.

a expansão da oferta de escolas consistentes que atendam a toda a população significa que o saber deixa de ser propriedade privada para ser socializado. Tal fenômeno entra em contradição com os interesses atualmente dominantes. Daí a tendência a secundarizar a escola, esvaziando-a de sua função específica, que se liga à socialização do saber elaborado, convertendo-a numa agência de assistência social, destinada a atenuar as contradições da sociedade capitalista. (SAVIANI, 2011, p.85)

E é desta manutenção da funcionalidade da escola que a corrente histórico crítica se contrapõe, ou seja, fortalecer a compreensão do ensinamento, de conteúdos e de conhecimentos científicos onde possa ter a igualdade social como resultante, onde aja a real igualdade entre todas e todos, onde a educação sirva para acabar com a naturalização das desigualdades estruturantes, necessária para o sistema capitalista (SAVIANI, 2011). Desta forma, busco incentivar um olhar crítico sobre este processo que ocorre de maneira automatizada e, habitualmente, carente de embates e questionamentos.

Com este intuito, as instituições escolares se mantêm neste sistema para buscar moldar e transmitir normas de condutas sociais, assim, as escolas acabaram por ganhar força no mundo capitalista. O objetivo crucial para tais instituições é demarcar possibilidades, normas, conteúdos e conhecimentos científicos para determinadas classes.

Por outras palavras, a Escola (mas também outras instituições de Estado como a Igreja ou outros aparelhos como o Exército) ensinam "saberes 
práticos" mas em moldes que asseguram a sujeição à ideologia dominante ou o manejo da "prática" desta. (ALTHUSSER, 1980, p.22)

A escola tornou-se o Aparelho Ideológico do Estado número um após sangrentas lutas de classes, pois a escola possui normatizações e conhecimentos desde tenra idade, surge como um papel social majestoso para impor, de forma sutil, os ideais que mantém o sistema capitalista. Trazendo ideologias dominantes relacionadas a cada classe com o simples objetivo de manter a ordem de exploração que o sistema necessita para manter-se vigente. Transformando a sujeição à ideologia dominante como algo intrínseco (ALTHUSSER, 1980).

Portanto, ao pensar em instituições escolares que primam pela democracia popular, se deve pensar em escolas que tragam com si a ânsia pela curiosidade e pelo conhecimento livre, pela ampliação histórica e contextualizada do ensinamento, onde a verdade traga consigo a libertação de uma classe (SAVIANI, 2011). Onde não seja o tempo sua amarra ou ainda para que classe social esta se destina. O conhecimento deve fluir por indivíduos, relacionando a sua prática social, fazendo sentido a sua existência e trazendo uma gama de possibilidades para todas as pessoas. Inclusive deveria ser redundante falar de educação e democracia, mas infelizmente, no nosso contexto atual, não é (SAVIANI, 2012).

Importante salientar que a instituição escolar serve como Aparelho Ideológico do Estado, mas não sozinha, ou seja, tem função ideológica precisa e cirúrgica na manutenção de poderes, porém não seria possível sustentar sozinha, todo o aparato que o sistema capitalista requer para se manter no poder. Por este motivo, também não podemos crer que o inverso também pode ocorrer, a escola sozinha não pode ser vista como redentora da sociedade. Deve ser pensada e praticada a pedagogia revolucionária ${ }^{\text {iii }}$, para auxiliar na democratização de conhecimentos e compreensão da realidade social das(os) estudantes (SAVIANI, 2012), mas não se enganar que a escola isoladamente, fará a revolução, seria um fardo muito pesado para nós professores(as).

Saviani (2012) nos alerta que a pedagogia focada somente na essência dos alunos e das alunas, transforma-se atuação carente de conteúdo, o que fragiliza o conhecimento necessário para uma modificação social. Pois, não há uma possibilidade real para o cerceamento da sociedade de classes se o conhecimento científico continuar concentrado num pequeno grupo dominante. $\mathrm{O}$ autor também nos alerta que trazer o conhecimento científico como prioridade, acaba por afastar as chances de conhecimento para todas e todos, pois não há possibilidades iguais e democráticas para todas(os) no atual momento (e que não caiamos nas garras de um pensamento meritocrático). 
artes de

educar

Aqui é necessário fazer uma pausa e digerir o que já foi explanado neste estudo, pois há a necessidade constante de ligarmos os pontos para ter a compreensão do quanto eles são intrínsecos, porém individuais. Então, vamos lá: a sociedade atual utiliza da democracia capitalista para ornar uma sociedade que vivencia um fascismo social (SANTOS, 2009), ou seja, através de uma democracia, que só visa beneficiar a classe dominante, o Estado busca alternativas que faça o explorado sentir-se satisfeito e grato pelo pouco (ou quase nada) que se tem; para reforçar este entendimento de que é preciso ser grato ao que se tem, existem os Aparelhos Ideológicos do Estado (ALTHUSSER, 1980), que trazem comportamentos adequados para cada classe social, e a escola é um importante Aparelho por estar disponível para todas as comunidades, desde os primeiros anos de vida, facilitando uma doutrinação de pensamentos e querências.

Através deste entendimento, fica configurada a importância de uma educação democrática e crítica (adjetivos redundantes para uma pedagogia revolucionária) (SAVIANI, 2012) para a ampliação de possibilidades de conscientização da classe operária frente a escravidão que a mesma sofre, para romper as correntes mais cruéis que nos prendem, a ideologia capitalista. Pensando nesta junção de conhecimentos trazidos até aqui, iremos relacionar com o momento da pandemia que o mundo vive.

\section{Educação e coronavirus}

Nada do que foi trazido aqui, até o momento, é conhecimento inédito. A partir dessas linhas, buscarei fazer uma interseção da teoria histórico crítica, apresentada até aqui, com a realidade que nos cerca no momento. A conjuntura atual traz um momento de isolamento social, onde a negação do contato físico entre as pessoas oferece uma nova (e estranha) forma de se relacionar, principalmente para os países latinos (como no caso do Brasil), onde o abraço, aperto de mão, beijos de chegadas e de saídas, são comuns, rotineiros e fazem parte do nosso comportamento. Essa mudança de hábitos é apenas uma entre as tantas exigidas para evitar o contágio pelo coronavirus, um vírus que se aloca no corpo humano e deflagra a temida doença Covid-19 (BRASIL, 2020).

Esta doença tem trazido novas formas de relações sociais para o mundo, trabalhos que eram feitos presencialmente em escritórios, se transformaram em home office para evitar deslocamento de pessoas pela cidade. Assim como as escolas foram fechadas, diminuindo a concentração de pessoas em tais ambientes, essas medidas foram tomadas de forma certeira, com o intuito de evitar um contágio desordenado. Este receio ocorre pelo motivo da Covid-19 


\section{artes de}

educar

ser uma doença que, rotineiramente, necessita de um aparato hospitalar que envolve tempo de recuperação em Unidade de Tratamento Intensivo. Então há a preocupação de existir um colapso na área da saúde se houver um grande número de contágio ao mesmo tempo (CANABARRO et al, 2020).

Assim, com as modificações necessárias para manter o isolamento social possível na sociedade, trabalhos, cursos, escolas, etc. tiveram e estão tendo que se reinventar. Nosso foco aqui é no ambiente escolar, interrogações sobre: como essas instituições estão agindo nesses tempos de pandemia? Como a educação tem reagido? Qual tem sido o sentido da educação escolar neste processo incerto de tempos atípicos? Como a pedagogia revolucionária pode ser fundamental neste processo?

No Brasil temos o seguinte cenário, de uma forma panorâmica e geral: aulas presenciais suspensas, mas não necessariamente aulas remotas/domiciliar/não presencial/entre outras nomenclaturas em seu lugar. Como se pode observar na nota de esclarecimento do Conselho Nacional de Educação (CNE) de dezoito de março de 2020, início da tentativa do isolamento social no país:

no exercício de sua autonomia e responsabilidade na condução dos respectivos projetos pedagógicos e dos sistemas de ensino, compete às autoridades dos sistemas de ensino federal, estaduais, municipais e distrital, em conformidade com o Decreto $\mathrm{n}^{\circ}$ 9.057, de 25 de maio de 2017, autorizar a realização de atividades a distância nos seguintes níveis e modalidades:

I - ensino fundamental, nos termos do $\S 4^{\circ}$ do art. 32 da Lei $n^{\circ} 9.394$, de 20 de dezembro de 1996;

II - ensino médio, nos termos do $§ 11$ do art. 36 da Lei nº 9.394, de 1996;

III - educação profissional técnica de nível médio;

IV - educação de jovens e adultos; e

V - educação especial. (BRASIL, 2020b)

Toda a Educação Básica, como também a Educação Universitária (como descrito no tópico quatro da mesma nota "[...] as instituições de educação superior podem considerar a utilização da modalidade EaD como alternativa à organização pedagógica e curricular de seus cursos de graduação presenciais."), foi atribuída a modalidade não presencial de ensino, e com isso vieram demandas e problematizações desta prática, que em muitas situações foi estipulada de forma aligeirada e sem a respectiva fundamentação ou aporte para a comunidade escolar (responsáveis, alunas(os), professores(as), etc). Faz-se importante atentar que a modalidade de ensino não altera a função capitalista da educação escolar (SAVIANI, 2011). 
artes de

educar

As instituições e localidades que optaram ${ }^{\text {iv }}$ por adequar o ensino presencial ao remoto tiveram que ir adequando as demandas de acordo com o caminhar do processo, como escutei algumas vezes "tivemos que aprender a trocar o pneu do carro com o veículo em movimento!", e esta frase resume bem todo esse processo caótico. A manutenção das aulas, sem preparação prévia, priorizou a passagem de conteúdos de uma forma explicitamente bancária, como já repudiava nosso patrono da educação desde a década de 1980, quando definia a educação bancária como oposta a educação libertadora (FREIRE, 2012).

Para conseguir clarear, da melhor forma possível, o cenário do Brasil neste período, importante relatar que vivemos numa crise econômica (com o aumento de desemprego), uma crise política (com um atual presidente que busca omitir dados e repudia o diálogo aberto com a sociedade) e a crise sanitária (causada pelo Covid-19 por ainda não ter vacina ou remédio específico para tal doença) como mostram reportagens publicadas na Folha de São Paulov . Esta realidade social atravessa a escola, pois é neste contexto que ela está inserida, ou seja, possui as demandas de mudança de modalidade e forma de ensino de maneira abrupta e ainda possui pessoas da comunidade escolar passando por todas essas ingerências governamentais e inseguranças sociais.

Bom, já são três meses no processo de distanciamento social respeitado pelas escolas, e é este o período de uma tentativa de educação escolar que se tem para tentar analisar e compreender tal situação dentro da possibilidade temporal que nos cabe. Neste contexto, onde não há uma unidade de ação das redes de ensino (temos universidades e institutos federais, por exemplo, que optaram por não ministrar aulas remotas no momento), a maioria das redes de ensino optou por manter aulas remotas, trazendo uma tentativa de manter uma normalidade do processo, o que desce como um engodo, para todas(os) envolvidos(as). Fica claro, mais uma vez, que o processo de ensino e aprendizagem é uma via de mão dupla (no mínimo), onde há a necessidade de trocas de informações e vivências, não somente o despejo de conteúdos. Não se deve menosprezar os conhecimentos científicos, mas também não se deve hipervaloriza-lo (SAVIANI, 2012).

Que educação estamos pretendendo através das telas frias dos computadores, onde no início de cada "aula" pede-se para que desliguem os microfones virtuais e escutem os ensinamentos? Educadores(as) do Brasil, tem lecionado de forma distinta em salas de aula presenciais do que este formato virtual? Como definiremos uma qualidade para a educação se o objetivo é apenas passar conteúdos para educandos(as) que nem sabemos se tem acesso a internet ou condições salubres para acessá-la em casa? 
Para começar a clarear qual a real funcionalidade deste formato de educação que chamarei, a partir de agora, de educação ilusória, trarei o recente parecer do CNE, mostrando que tais aulas remotas poderão e deverão ser contabilizadas como aulas dadas pelo calendário escolar.

Tradicionalmente no Brasil, quando há suspensão das aulas, ocorre, posteriormente, reposição presencial, como decorrência natural de ser esta a forma de ensino predominante para a Educação Básica, conforme estabelecida pela LDB. Porém, considerando a possibilidade de uma longa duração do período de emergência [isolamento social], pode haver dificuldades para uma reposição que não impacte o calendário de 2021 e que também não acarrete retrocesso educacional para os estudantes.

Por isso, o CNE recomenda que sejam permitidas formas de reorganização dos calendários utilizando as duas alternativas [presencial e não presencial] de forma coordenada, sempre que for possível e viável para a rede ou instituição de ensino, do ponto de vista estrutural, pedagógico e financeiro. (BRASIL, 2020c)

Ao pensar e ratificar uma quantificação de aulas e conteúdos com o atual cenário brasileiro, o CNE reforça a educação ilusória e fomenta a desigualdade social, mesmo dizendo-se contra tal ato. Pois, possuímos uma realidade social caótica, como já foi relatado, e ainda uma exclusão digital que atinge mais de $1 / 3$ (mais de $70 \%$ ) da população brasileira, onde mesmo havendo um aumento, temos um grande quantitativo de domicílios sem acesso a internet. Como podemos ver a seguir:

Enquanto, em 2008, apenas $18 \%$ dos domicílios brasileiros contavam com acesso à rede, estima-se que, em 2018, cerca de $67 \%$ do total de domicílios estavam conectados - o que representa 46,5 milhões de domicílios e seis pontos percentuais a mais do que o verificado em 2017 (61\%). (BRASIL, 2019, p. 104) [grifo meu].

Mas, ouso dizer que por mais difícil que seja resolver a dificuldade de acesso à internet para todas(os), acredito que, dentre os demais problemas, esse ainda é o mais simples de ser resolvido.Você pode se indagar o porquê dessa minha hipótese, e eu procurarei responder de uma forma prática. A educação no Brasil tem servido a mão invisível do mercado neoliberal, diretamente, desde 1990, cedendo espaços para o setor privado ou fazendo barganhas com as diretrizes curriculares nacionais em troca de investimentos estrangeiros. Agora, pensem o quanto nossa educação, nessas quatro décadas, já teve que se fantasiar de democrática e acessível para todas(os), imaginem as marcas deixadas em quatro décadas de luta por uma educação pública de qualidade de uma pequena parcela social, contra 
o gigante neoliberal. Pensem que no processo democrático capitalista a instituição deve sempre servir ao Estado (QUIJANO, 2002) e este Aparelho Ideológico do Estado (ALTHUSSER, 1980) tem engrenagens tão naturalizadas que fica difícil de imaginar um futuro sem as mesmas para a maioria das pessoas. Por isto, compreendo que gerir políticas públicas que dêem acessibilidade à internet para todas as pessoas, necessita de uma demanda menos "problemática" para o sistema atual do que rever os sentidos e significados de uma educação pública realmente democrática.

Santos (2020) tem conceituado o momento mundial pandêmico, com as mortes sendo majoritariamente nos setores pobres e periféricos, como uma expressão do darwinismo social, onde morre mais pessoas subalternizadas, marginalizadas e invisíveis, não pela seleção natural, mas pela naturalização do sistema capitalista.

Grande parte da população do mundo não está em condições de seguir as recomendações da Organização Mundial de Saúde para nos defendermos do vírus porque vive em espaços exíguos ou altamente poluídos, porque são obrigados a trabalhar em condições de risco para alimentar as famílias, porque estão presos em prisões ou em campos de internamento, porque não têm sabão ou água potável, ou a pouca água disponível é para beber e cozinhar, etc. $(\mathrm{s} / \mathrm{p})$

Segundo o autor, o darwinismo social visa destruir os mais pobres de diferentes formas, com a morte física, com a morte social, com a morte moral, com a morte econômica. E, para esta análise, é importante lembrar que o ensino escolar está intrinsecamente relacionado com esta contextualização social, logo, o darwinismo social engloba uma dose de darwinismo educacional também. Pois, a escola continua como importante Aparelho Ideológico do Estado (ALTHUSSER, 1980) e suas amarras têm sido cada vez mais diretas e claras em detrimento do que o Estado almeja para cada classe econômica e social.

Assim, dentro desta contextualização histórico crítica, fica escancarado os pretensos planos para a educação pública, direcionada para as classes subalternas da sociedade, ou seja, acaba por dificultar o acesso à educação escolarizada para essa classe, dificultando o aprendizado crítico e consciente desses alunos(as), invibializando a pedagogia revolucionária. Por esse motivo, educadores(as) que apóiam o viés crítico(a), devem focar suas energias em um projeto educacional onde se tenha o foco em servir a classe trabalhadora, e não a quem está no topo da hierarquia social. 
No próximo tópico o debate girará em torno da necessidade de um novo projeto educacional, será debatido sobre a urgência de conflitos acerca das demandas educacionais voltadas para uma democracia real e crítica, onde o foco seja a igualdade social.

\section{Por um novo projeto educacional}

Não me cabe aqui, inventar este novo projeto educacional, o que tenho feito, parte do princípio de juntar peças já expostas por um cenário de estudiosas(os) mundiais e relacioná-las com o período conturbado que estamos passando, mostrando que há uma necessidade urgente das(os) trabalhadoras(es) da educação se moverem em prol da sua classe (trabalhadora), por que se não for feito isso agora, neste exato momento, teremos cada vez mais uma educação pública precária para nossa gente. Para isso, resgatei teorias e falas que corroboram com a minha leitura sobre o fato, e espero estar honrando tais pesquisadoras(es).

Saviani (2012) já alertou como o sistema capitalista pode ser sedutor em suas palavras e currículos para auxiliar a reforçar os ideais de seu sistema, mostrando sua potencia política, mas sem ter uma visão turva sobre essa cumplicidade, pois, segundo o autor, a frase "educar é um ato político", pode ser distorcida até virar pó e se esvair entre os dedos. Por isso, retrata a necessidade de uma avaliação crítica de professores(as) para haver uma efetiva atuação que vise a classe trabalhadora, mas sem excluir todo envolvimento social neste processo, ou seja, não se deve cair na inocência de acreditar que a educação, por si só, isolada da sociedade, pode mudar a própria sociedade.

[...] se não acredito que a desigualdade pode ser convertida em igualdade pela mediação da educação (obviamente não em termos isolados, mas articulada com as demais modalidades que configuram a prática social global), então, não vale a pena desencadear a ação pedagógica. (SAVIANI, 2012, p. 78)

Precisa-se ter a consciência das reais competências que cabe no ambiente escolar, não se deve expor educadores(as) como responsáveis únicos(as) por um processo de conscientização de classe, como também docentes não podem ser vistos como pessoas que 


\section{artes de}

educar

estão na escola apenas para passar conteúdos. Assim, fica claro que a educação escolar nesta pandemia, tem reproduzido objetivos específicos para a manutenção da ordem social capitalista, reforçando o ideal meritocrático e o darwinismo educacional. Sendo banida a democratização à educação de diversas formas, o que acaba por reforçar e aumentar toda a exclusão educacional que já existia.

Ao citar a democracia neste momento, preciso trazer para a conversa a autora que mostra como a democracia (no seu sentido literário) é incompatível com o sistema capitalista, justamente por significar "poder popular" ou "governo do povo", Ellen Wood (2007). Desta forma, facilita a nossa compreensão que quem luta pela democracia, por uma educação democrática, necessariamente visa um mundo livre do capitalismo e que vivencie um estado sem sujeições.

Isso significa que o capitalismo necessariamente situa cada vez mais esferas da vida cotidiana fora do parâmetro no qual a democracia deve prestar conta de seus atos e assumir responsabilidades. Toda prática humana que possa ser convertida em mercadoria deixa de ser acessível ao poder democrático. Isso quer dizer que a democratização dever da mão da "desmercantilização". Mas desmercantilização por definição significa o final do capitalismo. (WOOD, 2007, p. 418)

Mas, se eu partir de uma compreensão de que todas as pessoas licenciadas (aptas para lecionar em escola) possuem conscientização de classe, estaria desmerecendo todo o aparato de todos os Aparelhos Ideológicos do Estado, ou seja, não há, e nem nos devemos enganar achando que há, uma relação direta entre conscientização de justiça social e escolarização. A consciência de classe passa muito mais por uma história de vida do que por uma formação escolarizada, mas também, não exclusivamente.

Por este motivo, este momento tende ser tão crucial na reestruturação de uma educação que vise priorizar a classe trabalhadora, e que possa caminhar em conjunto com uma modificação de visão social que existe na sociedade. Não há mais como fechar os olhos para as barbaridades que o sistema capitalista obriga a classe trabalhadora a fazer (SANTOS, 2020), que reflete numa educação direcionada para a manutenção dos(as) explorados(as) enquanto explorados(as).

Enquanto modelo social, o capitalismo não tem futuro. Em particular, a sua versão actualmente vigente- o neoliberalismo combinado com o domínio do capital financeiro - está social e politicamente desacreditada em face da tragédia a que conduziu a sociedade global e cujas consequências são mais 
evidentes do que nunca neste momento de crise humanitária global. (SANTOS, 2020, s/p)

A educação neste momento deve atrever-se e caminhar em prol à passagem de conteúdos democráticos e críticos de seus conhecimentos científicos (SAVIANI, 2012), e não podemos esperar essa preocupação dos(as) governantes do sistema, essa ação deve partir de círculos de debates e de grupos de conscientização. Esta aflição com a prática docente, com a ação pedagógica, deve tirar o sono dos trabalhadores e das trabalhadoras educacionais, não com o sentido de causar doenças gástricas ou psíquicas, mas com o intuito de motivar esses(as) a selecionar conteúdos, debates e espaços para conscientização crítica de educandas(os), buscando relacionar essa realidade doída que estamos passando, em um momento de crise gerado, causado e fomentado por um sistema econômico e político que pensa somente em barganhar pessoas para torná-las coisas e consumi-las (WOOD, 2007).

A questão que pode estar a passar pela cabeça de educadores(as) que me lêem nesse momento é: "e como será a passagem dos conteúdos curriculares cobrados pelos governos (em forma de avaliações externas)?" E neste momento peço que o trabalho se valha da luta maior por uma igualdade social, peço que este conteúdo seja ensinado, visto e revisto com esse viés crítico, pois não adianta mais ensinarmos os(as) alunos(as) a memorizar números, letras, exercícios, cores, espaços geográficos, etc. (educação ilusória) se os(as) mesmos(as) não conseguem fazer essa leitura nesse mundo golpeado que nos encontramos. A valorização do trabalho docente parte da ação social, fomos (eu e você) enganados(as) muito tempo achando que os conteúdos, as notas, a hierarquização, o potencial para memorização, são o foco principal da escola. Nossa premissa está relacionada diretamente com a humanização do processo. "Ora, em meu modo de entender, tal contribuição será tanto mais eficaz quanto mais o professor [e a professora] for capaz de compreender os vínculos da sua prática com a prática social global.” (SAVIANI, 2012, p.80)

Se a desconsideração da prática humana for contínua e reforçada neste período de pandemia, o processo frio e virtual tenderá a substituir cada vez mais as(os) educadoras(es) em pouco tempo, pois o mesmo pode ser programado (por ser máquina), de forma mais direta e calculada, a passar um conteúdo específico e avaliar tecnicamente se o aluno e a aluna são capazes de reproduzi-los. Um paraíso para a classe dominante onde o foco em futuros(as) cidadãos(ãs) alienados é o ápice. Fincando o fascismo social (SANTOS, 2009) como oficial.

Por este motivo, as(os) docentes com consciência de classe devem se mobilizar neste momento para, através das lacunas do sistema imposto, conseguir trazer conhecimento social 
para os(as) educandos(as) que tem a possibilidade de continuar neste processo de forma remota. Este colapso social deve formar novas trincheiras de resistência, dentro do processo educacional (como em outros setores da sociedade), pois se formos esperar um currículo preocupado em conscientizar a classe trabalhadora, ou que ensine sobre as sutilezas da alienação social (MARX; ENGELS, 1999) vinda da classe dominante, deixaremos o trator capitalista/neoliberal passar por cima de diversos corpos periféricos.

Não devemos aguardar ou esperar um novo projeto educacional da classe dominante, devemos sim, unir as nossas ideias e forças em debates que resultem em possibilidades de fortalecer a educação pública, para ter conteúdos trabalhados de forma que não seja colonizada ou colonizadora (QUIJANO, 2002), nem que naturalize o processo de exploração de classes ou que ainda selecione conteúdos de aprendizados mínimos para a periferia e amplos para os demais, dando-lhes maior chance de conhecimento científico e manutenção de saberes divididos por classes.

A potência parte de nós, que somos maioria, classe trabalhadora. Não de um segmento social específico, pois se o capitalismo precisa de uma estrutura para se sustentar, para quem almeja sua queda, não pode pensar acertar-lhe só em um local. A prioridade é união de pessoas que tenham conscientização das desigualdades que transformam as linhas que separam cada grupo em uma linha abissal sinuosa (SANTOS, 2009), para buscar fortalecer a democracia no seu sentido genuíno.

Pode parecer utópico e uma conjectura que destoa das possibilidades apresentadas no momento. Mas, como um vírus se espalhou em menos de um ano por todo o território mundial, de uma forma globalizada, teimo em acreditar que ideias e ideais em prol da maior parte da população global (classe trabalhadora) pode disseminar e trazer realidade positivas e novas possibilidades humanizadas para todas as pessoas. Pois, está na hora de enxergarmos o capital como ele realmente é, sem suas máscaras ou maquiagens, mas um sistema que estipula sua manutenção de dentro para fora, coagindo e trazendo ideologias específicas. Se o capital depende de nós trabalhadores(as) para se fortalecer, fica fácil compreender quem pode implodi-lo, ainda mais considerando um mundo globalizado como o nosso.

o capital depende, talvez hoje mais que nunca, de um sistema global de Estados; as lutas verdadeiramente democráticas - entendidas como lutas para trocar o equilibrio de poder de classe tanto dentro como fora do Estadopodem chegar a ter um efeito muito maior que em épocas anteriores. (WOOD, 2007, 430) 
Para encerrar as ideias desse tópico, vou resumir de uma forma simples: este novo projeto educacional (que não é tão novo, mas necessita de uma nova roupagem) deve partir de uma vivência democrática no contexto atual pandêmico, expressando a realidade que cada estudante traz, para fortalecer a compreensão que não são todos(as) que passam pelos mesmos problemas e, muito menos, da mesma forma, gerando uma conscientização de classe; este ato não será pedido pelas secretarias de educação e nem sequer por seu ministério, partirá de docentes comprometidos(as) com a classe trabalhadora que encontrarão brechas para relacionar seus conhecimentos científicos específicos com tal fundamentação.

\begin{abstract}
A escola é, pois, compreendida com base no desenvolvimento histórico da sociedade; assim compreendida, torna-se possível a sua articulação com a superação da sociedade vigente em direção a uma sociedade sem classes, a uma sociedade socialista. É dessa forma que se articula a concepção política socialista com a concepção pedagógica histórico-crítica, ambas fundadas no mesmo conceito geral de realidade, que envolve a compreensão da realidade humana como sendo construída pelos próprios homens, a partir do processo de trabalho, ou seja, da produção das condições materiais ao longo do tempo. (SAVIANI, 2011, p.88)
\end{abstract}

Logo, em tempos tão sombrios, importante relatar que não se trata de uma doutrinação onde estarão certos apenas os(as) alunos(as) que pensem igual aos(as) docentes, mas que seja um período que sirva de reflexão num momento tão propício para falarmos sobre, pois os corpos periféricos são os que mais estão sofrendo com esta pandemia (SANTOS, 2020). Que esta utopia sirva também de reflexão para professoras(es) preocupadas(os) com o futuro da classe trabalhadora e todos(as) que compõem os segmentos que também servem de Aparelho Ideológico do Estado.

\title{
Reflexões
}

A pandemia é um mal que tem causado milhares de mortes pelo mundo e ainda não tem vacina ou remédios específicos para a sua cura ou tratamento. Sendo assim, temos uma imprevisibilidade acerca do tempo que ainda se terá para o processo educacional fora do ambiente escolar. Esta leitura, neste momento, se faz necessária para a compreensão de como o fato social está influenciando, de forma direta, este processo. É preciso que se atente para a complexidade desta crise, para que se possa efetivamente, criar possibilidades que sejam plausíveis para todas as pessoas, principalmente para evitar mais desigualdades sociais no ambiente escolar. 


\begin{abstract}
Essa formulação envolve a necessidade de se compreender a educação no seu desenvolvimento histórico-objetivo e, por consequência, a possibilidade de se articular uma proposta pedagógica cujo ponto de referência, cujo compromisso, seja a transformação da sociedade e não sua manutenção, a sua perpetuação. Esse é o sentido básico da expressão pedagogia históricocrítica. Seus pressupostos, portanto, são os da concepção dialética da história. Isso envolve a possibilidade de se compreender a educação escolar tal como ela se manifesta no presente, mas entendida essa manifestação presente como resultado de um longo processo de transformação histórica. (SAVIANI, 2011, p. 80)
\end{abstract}

Como foi visto neste artigo, esse momento é crucial para educadoras(es) engajadas(os) na igualdade social, utilizar da experiência que as classes periféricas trazem, para mostrar como a injustiça social massacra, cada vez mais e de diferentes formas, e especificar que não é algo natural e que não deve ser encarado como vontade divina, mas sim como uma demanda exploratória do sistema econômico, político e social vigente. Logo, deve-se explanar e relatar sobre o que deve ser modificado para haver a preservação da vida e a extinção de tempos de sobrevivências para a maioria em prol de poucos.

Com isso, a conjectura para a educação escolarizada neste momento pandêmico, reflete num novo projeto educacional que deve partir da manifestação e inquietação de todas as pessoas que realmente se preocupam com o próximo e que tem consciência de classe, utilizando os ensinamentos científicos na fortificação da classe trabalhadora. Sem se preocupar em ter a unanimidade do pensamento, mas apontando que contra fatos não há argumentos, e que com a ampliação da visão do atual cenário, facilita o entendimento das pessoas que há valorização distinta para vida, dependendo da classe que se vive.

Pois, como na introdução deste trabalho, que foi relatado sobre a dubiedade que a experiência virtual pode trazer neste momento, é possível e necessário que pessoas comprometidas com a igualdade social, direcionem suas forças para o que esta experiência (dolorosa) possa trazer ensinamentos de toda uma classe. Criando um paralelo da educação escolar com as visitas aos museus, mesmo que falte o contato físico com nossas(os) educandas(os), o alento, a troca direta, precisamos aproveitar a possibilidade de ampliar os horizontes de conhecimento social neste momento.

Neste trabalho, o foco foi falar sobre a educação, mas o comprometimento deve partir de todos os setores envolvidos com experiências que traga possibilidades ampliadas, crítica e conscientes neste momento de pandemia e sofrimento social. O processo possui diversas demandas e formas de aplicação, e também não tem receita de bolo, a sua prioridade é a 
realidade que os(as) estudantes trazem e como isto será a ferramenta para professores(as) críticos e democráticos para facilitar a compreensão que o sofrimento passado por eles(as) não é uma sentença, e sim imposto por um pequeno número de pessoas que se beneficiam com o sofrimento alheio.

Com essas linhas, espero aglutinar a minha utopia com outros pensamentos similares para nos unirmos cada vez mais e debatermos sobre uma justiça social possível, onde o ato de algumas pessoas "precisarem", por exemplo, pegar transportes públicos lotados no meio de um isolamento social, por exemplo, não seja visto com conformidade. Compreendo que a minha visão não será enaltecida por todas(os), mas prefiro acreditar que mostrar a realidade para a classe trabalhadora, trará o frescor da esperança e com isso alguma mobilização para que tenhamos dias melhores, com ou sem pandemia, mas que se houver justiça e igualdade, será mais leve e honesto.

Que sigamos na plenitude de nossos sonhos e querências.

\section{Referências}

ALTHUSSER, Louis. Ideologia e aparelhos ideológicos de Estado. Lisboa: Editorial Presença, 1980.

BRASIL. Pesquisa sobre o uso das tecnologias de informação e comunicação nos domicílios brasileiros: TIC domicílios 2018. São Paulo: Comitê Gestor da Internet no Brasil, 2019. Disponível em: $<$ https://www.cetic.br/media/docs/publicacoes/2/12225320191028tic dom_2018 livro_eletronico.pdf $>$ Acesso em: 04 junho 2020.

. Ministério da Saúde. Tem dúvidas sobre o coronavírus?, 2020a. Disponível em $\overline{<\text { https://www.saude.gov.br/images/pdf/2020/April/07/Cartilha-Coronavirus-Informacoes- }}$ .pdf> Acesso em: 02 junho 2020.

. Ministério da Educação. Conselho Nacional de Educação. Nota de esclarecimento. 2020b. Disponível em: $<$ http://consed.org.br/media/download/5e78b3190caee.pdf $>$ Acesso em: 02 junho 2020.

. Parecer $n^{0}$ 5/2020, de 28 de abril de 2020c. Reorganização do Calendário Escolar e da possibilidade de cômputo de atividades não presenciais para fins de cumprimento da carga horária mínima anual, em razão da Pandemia da COVID-19. Disponível em:

$<$ http://portal.mec.gov.br/index.php?option=com docman\&view $=$ download\&alias $=145011$ pcp005-20\&category_slug=marco-2020-pdf\&Itemid=30192> Acesso em: 02 junho 2020.

CANABARRO, Askery; TENPORIO, Elayne; MARTINS, Renato; MARTINS, Lais; BRITO, Samurai; CHAVES, Rafael. Data-DrivenStudyofthethe COVID-19 Pandemic via Age-StructuredModellingandPredictionofthe Health System Failure in BrazilamidDiverseInterventionStrategies. Medrxiv. Disponivel em 
educar

$<$ https://www.medrxiv.org/content/10.1101/2020.04.03.20052498v1.full.pdf $>$ Acesso em: 09 jun 2020 .

FREIRE, Paulo. Pedagogia do oprimido. Rio de Janeiro: Nova Fronteira, 2012.

GIL, Antônio Carlos. Métodos e técnicas de pesquisa social. São Paulo: Atlas, 2008.

HOOKS, bell. Erguer a voz: pensar como feminista, pensar como negra. São Paulo: Elefante, 2019.

MARX, Karl; ENGELS, Friedrich. O manifesto comunista. Edição RidendoCastigat Mores. Versão para eBook: eBooksBrasil.com. Fonte Digital: RocketEdition de 1999. Disponível em: $<$ http://www.ebooksbrasil.org/adobeebook/manifestocomunista.pdf $>$. Acesso em: 10 maio 2020 .

MOREIRA, Eduardo. Desigualdade e Caminhos para uma Sociedade mais justa. Rio de Janeiro: Civilização Brasileira 2019.

QUIJANO, Aníbal. Colonialidade, poder, globalização e democracia. Revista Novos Rumos, Ano 17, n 37, 2002. Disponível em:

$<$ https://revistas.marilia.unesp.br/index.php/novosrumos/article/view/2192> Acesso em: 08 jun 2020 .

SANTOS, Boaventura de Sousa. Para além do pensamento abissal: das linhas globais a uma ecologia de saberes. In: SANTOS, Boaventura de Souza; MENEZES, Maria Paula.

(Org.). Epistemologias do Sul. Coimbra: Almedina, 2009. p. 23-71.

. Direitos Humanos, democracia e desenvolvimento. In CHAUÍ, Marilena; SANTOS, Boaventura de Sousa. Direitos humanos, democracia e desenvolvimento. São Paulo: Cortez, 2014.

. A cruel pedagogia do vírus. Coimbra: Almedina, 2020.

SAVIANI, Dermeval. Pedagogia histórico-crítica: primeiras aproximações. Campinas, SP: Autores Associados, 2011.

. Escola e democracia. Campinas, SP: Autores Associados, 2012.

WOOD, Ellen Meiksins. Capitalismo e democracia. Buenos Aires: CLACSO, 2007.

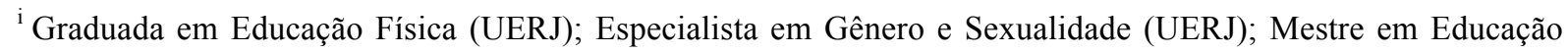
(UFRJ); Professora efetiva Universidade Estadual de Montes Claros (UNIMONTES). Montes Claro. Brasil. Email para contato: carla.ramalho@unimontes.br; ORCID https://orcid.org/0000-0002-6263-2498

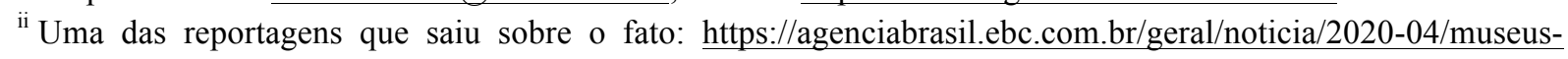
promovem-visitas-virtuais-durante-pandemia

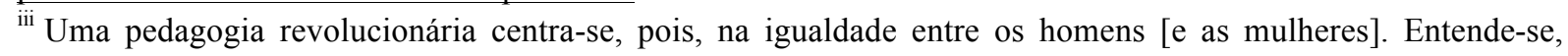
porém, a igualdade em termos reais e não apenas formais. Busca converter-se, articulando-se com as forças emergentes da sociedade, em instrumento a serviço instauração de uma sociedade igualitária. Para isso, a pedagogia revolucionária, longe de secundarizar os conhecimentos descuidando de sua transmissão, considera a
} 


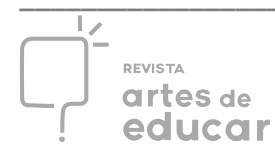

difusão de conteúdos, vivos e atualizados, uma das tarefas primordiais do processo educativo em geral e da escola em particular" (SAVIANI, 2012, p.65).

iv Algumas instituições de ensino optaram por suspender o calendário ao invés de impor uma educação remota aos seus e suas estudantes. Como podemos observar, na data de hoje (09 de julho de 2020), temos 41 institutos federais no território brasileiro e 28 desses institutos estão com as atividades suspensas (http://portal.mec.gov.br/coronavirus/).

${ }^{v}$ Disponível em: https://www1.folha.uol.com.br/mercado/2020/05/desemprego-aumentou-em-12-estados-comavanco-do-coronavirus.shtml e https://www1.folha.uol.com.br/equilibrioesaude/2020/06/segundo-especialistasgoverno-comete-crime-ao-omitir-dados-de-covid-19.shtml?origin=folha 